\title{
Thinking differently about orthodontics
}

\author{
J. Philippe
}

\begin{abstract}
The face is an organ that has two roles: to provide a set of functions, and to shape the subject's appearance. It is a living organ. Its components can develop, are often mobile and always diverse. Conventional diagnostic methods entail a frozen representation, in order to be measurable, thus ignoring life. The goal of orthodontic treatment is not to correct a structural abnormality, but to enable perfect function and to improve appearance.

The mechanical part of the treatment can be improved and simplified by digital tools and replacement of bows and brackets by elastopositioning.
\end{abstract}

\section{KEYWORDS}

Bracket, orthodontic diagnosis, elastopositioning, face, goal of orthodontic treatment

\section{INTRODUCTION}

It is all too human a weakness to believe that our way of understanding orthodontics, shared with others and formed by others, will be the way all orthodontists understand their field tomorrow. The present article aims to challenge the reader questionning the classic idea of orthodontic treatment and moving ahead toward what we would suggest is progress.

\section{THE FACE}

The first point is to understand the face.

The face is not an assembly of cephalometric angles. It is an organ - a living organ.
As an organ, the face plays two main roles and should be assessed and if necessary treated according to the fulfilment of these two roles.
Address for correspondence:

Julien Philippe - 6 rue Chanzy

28000 Chartres, France;

E-mail: julien.philippe28@wanadoo.fr
Article received: 8-10-2014. Accepted for publication: 30-11-2014.

This is an Open Access article distributed under the terms of the Creative Commons Attribution License (http://creativecommons.org/licenses/by/4.0), which permits unrestricted use, distribution, and reproduction in any medium, provided the original work is properly cited. 


\section{The first role of the face}

The first role of the face is to ensure all of the physiological functions it contains. Orthodontists check functions in the oral sphere. The first is respiration, which is rightly much discussed. Secondly, there is suction, which is not discussed as much as it should be, and then swallowing, which was discussed 30 years ago, phonation and mastication. The most recent to emerge is occlusion, affected by deficits in the more well-recognized functions.

The first aim of treatment is to ensure the perfect exercise of these functions.

\section{The second role of the face}

The second role of the face is to shape the subject's appearance. The face is the only part of our body that is on show to others. It is the organ of relational life. A poor appearance is a handicap in social life and an attractive face is an advantage.

Improving appearance is the second aim of treatment.

\section{The defining characteristics of life}

The defining characteristics of life is to develop, be mobile and diverse.

Living creatures are constantly in development. For this reason, the face should be studied in its four dimensions, the last of which, time, is the most important. The notion of time is essential in treating subjects in their growth phase, and who actually change their dentition, is one wishes the results of treatment to be lasting and to blend into the processes of maturation and senescence.

\section{To be alive is to be mobile}

Smiles and facial expressions are constantly moving the covering facial tissue. We have to see these tissues as sliding over the skeleton in a ceaseless to-and-fro reminiscent of windscreen wipers in the rain. The tongue wriggles and rolls all over the place, like a piece of clothing in the drum of a washing machine. Cineradiography reveals the mandible dancing apparently wildly. Implementing the ever-so convenient Angle classification and ever-so exact cephalometric measurements has given rise to the image of a face frozen in time, like an anatomy drawing - whereas in fact it is bursting with life.

\section{Diversity}

Another characteristic of life is diversity. Inanimate objects may sometimes be identical to one another; living creatures, never. Human beings, even when of the same age, gender and ethnicity, are always profoundly different from one another, in their genomes, shapes, sensibilities, intelligence and education. And, because they are different, it is impossible, and indeed absurd, to want them to come under a single set of morphological standards and measurements claimed to be "normal values". The quest for a single norm for all subjects should give way to a concept of "individual optimum". Fifteen years ago we wrote that there are 4,392 kinds of class II, 
division 1 malocclusion and therefore 4,392 treatments. In the same spirit, we are now saying that the orthodontist's job in not "correcting a malocclusion" but providing care for a "maloccluder".

\section{DIAGNOSIS}

Classical orthodontic diagnosis and its intellectual armamentarium were designed to recognize morphologic abnormalities, and inevitably lead to describing an abnormality in a freezeframe to enable measurement. The old "normality rules" have been replaced by cephalometric norms, but neither take on board evolution over time and mobility in space, just as the whole strategy of classification completely ignores the idea of diversity.

In our view, it is not a morphologic abnormality that calls for treatment, but rather its functional and esthetic consequences. Some treatments actually cause abnormalities (fewer teeth) and yet are accepted and even cheered if they improve function and esthetics. It is thus these two considerations that are important and justify treatment - not just a deviation from the norm. It is not the degree of morphologic variation that indicates and justifies treatment, but the degree of functional or esthetic discomfort that the variant is causing .

In classical orthodontics, it is cephalometry that discloses the structures deviating from mean values, proclaimed as "normal".

In our view, however, the usual way of interpreting cephalometric data is mistaken and leads to mistakes being made. When a cephalometric angle deviates from the mean, this is due to a variation in one of the three points determining the angle, and this may concern any of the three, and not just the one which interests the orthodontist. Thus, a variation in SNB angle may be due to a variation in $\mathrm{S}, \mathrm{N}$ or $\mathrm{B}$. Imagining that it is only point $B$ that varies is a misconception caused by the habit of taking $S$ and $\mathrm{N}$ as reference points for purposes of measurement. Registration on some other structure is all that is needed to reveal variation in these points. All the craniofacial points vary, as each head is a one-off model, different from any other and also different from the "mean"9. Thus, it is not cephalometric analysis that is going to identify what needs treating.

In classical orthodontics, the treatment objective is to conform the patient to the mean values, the "norms", set by cephalometry.

A mean value is a precise figure (SX/N) of descriptive value for a given population. How does this statistical parameter come to be set up as an ideal? Who wants to be "mean"? Men would like to be taller than average, women slimmer, with a smaller nose and larger eyes and whiter teeth. Everyone wants to be "above average". Moreover, the ideal for a face cannot be defined from a two-dimensional analysis excluding the transverse dimension and frontal view. 
The idea that the mean is a treatment objective needs replacing by the idea of an individual optimum.

To sum up, in our view it is the functional and/or esthetic impairment that needs treatment, rather than the morphologic abnormality - especially since the measurement of the abnormality is wrong and the treatment objective proposed (mean values) is devoid of interest. Morphology should be altered only inasmuch as the change is going to improve function or esthetics. It is only because ease of function depends on suitable morphologic conditions that the orthodontist goes to work on structures so as to optimize the interdependent form/function system.

Orthodontic diagnosis should no longer be founded on geometric

\section{ORTHODONTIC TREATMENT}

Orthodontic treatment has three objectives that are not dealt with here:

- functional quality (breathing, mastication, occlusion, etc.), which should be analyzed in detail, taking account of the development, mobility and diversity of its components;

- facial aspect, bearing in mind that there is no one standard of beauty and that the frontal view is more important than the lateral view as far as the patient is concerned;

- lasting results, which requires particular care from the beginning of treatment.

To achieve these three objectives, orthodontic treatment has 2 tools at considerations applied to an immobile image of the face but rather on a biological concept. The face should not be reduced to a profile represented by a set of numbers. It should be judged, assessed and treated according to the quality of its functions and its appearance in the eyes of self and others, with an emphasis on the frontal view. Some authors already assess the quality of each element of oral behavior on a scale from 1 to $5^{2}$.

The geometer's point of view should be replaced by the physician's outlook (a spirit of finesse, as Pascal would say).

If functions function well and the face is pleasant to look at, what does it matter if its angles match "standard" cephalometric values or not? Morphologic norms need to be left behind.

its disposal: rehabilitation of harmful behavior, and mechanical therapeutic devices.

\section{Myofunctional rehabilitation}

Rehabilitation applies to behaviors that are harmful either because they impair fulfillment of a function and thus jeopardize the patient's health, or because they induce esthetic harm.

The earlier the rehabilitation, the more effective. We have great faith in orthodontic rehabilitation of very young children, as described by Rollet $^{11}$ and Fellus ${ }^{3}$.

To ensure the patient's full cooperation, the practitioner needs a lot of 
psychology; it is no doubt by developing the relational aspect that rehabilitation will progress.

\section{Mechanics}

At present, in adults, morphologic alterations inspired by cephalometry are carried out by means of a bow fitted onto brackets. The bow-bracket set-up is esthetically displeasing, and unhygienic. It is not very effective for large displacements such as arcade expansion. It corrects class II relations by means of oblique elastic bands inducing egression of the maxillary incisors and mandibular molars. It does not achieve good intercuspation on the lingual side, especially regarding contact of the mesiopalatine cuspid of the two maxillary molars with the central fossa of the two mandibular molars, as bow adjustment to position the first molar has a contrary effect on the second due to the reciprocal anchoring system ${ }^{10}$.

\section{Mechanical treatment}

In our view, mechanical treatment should, if necessary, be divided into two steps: one to achieve large and apical displacements, and another to optimize intercuspation and alignment.

The first step is not always relevant, and will be decreasingly so as early treatments are developed, precisely intended to prevent dysfunction and dysmorphism. In adults, however, there will presumably continue to exist cases requiring large dental displacement beyond the capacity of the intercuspid devices used in the second step.

\section{Large and apical displacement}

Large and apical displacement require dedicated mechanical systems adapted to the desired movement. Thus, for arcade expansion, there is a whole range of devices (Quad Helix, palatal expander, etc.) that are more effective than edgewise bows. Canine retraction after extraction of a premolar and of the incisors has been transformed by the use of temporary implants. The most sophisticated set-up is that described by $\mathrm{Kim}^{6}$ and Hong $^{4}$ (Fig. 1 and 2). Correcting class II relations is greatly facilitated by the lever-arm systems populating the orthodontic literature. For treatment of deep-bite occlusion, we remain faithful to retroincisor blocks, prepared in the laboratory and balanced in the mouth?.

\section{Second step of treatment}

The second step of treatment (or the only step if the first is judged unnecessary) is intended to ensure perfect intercuspation and alignment. In our view, elastopositioning best achieves this on the lingual side, not visible in the mouth but essential to occlusion.

Computerization has revolutionized this part of treatment: digital orthodontics has become a must.

After optical imprints are taken, the software ensures alignment and intercuspation in the virtual arcades. A digitally created model allows the orthodontist to visualize the morphological elements involved in wellbalanced occlusion. The ease with which teeth are positioned in good relation with their antagonists should not lead to "standard" arcades being 


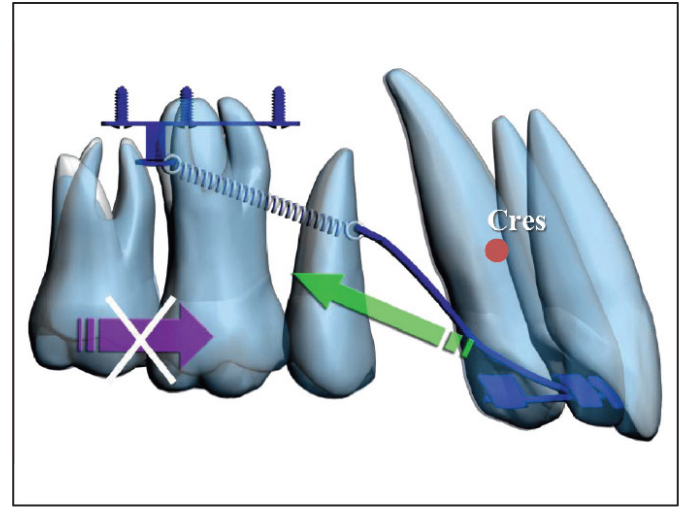

a

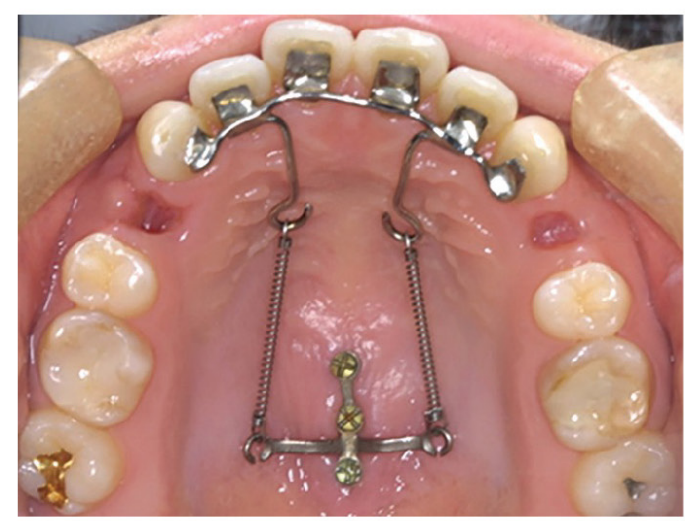

C

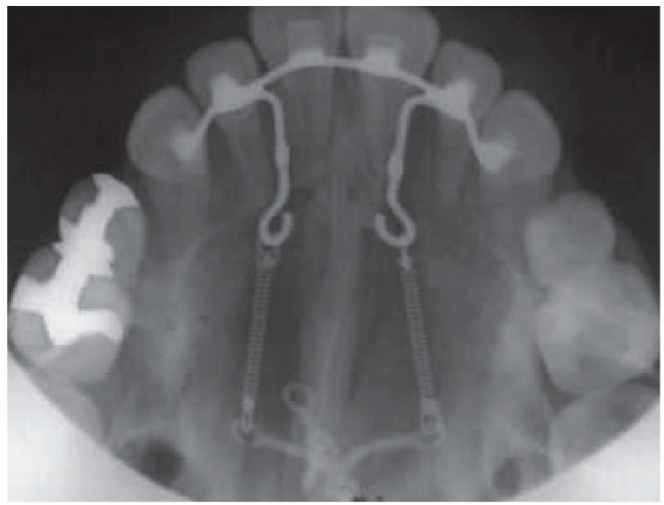

b

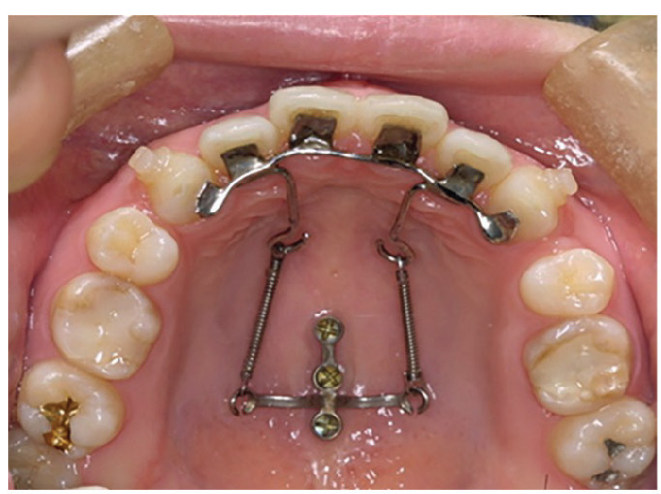

d

Figure 1

The incisor-canine block is pulled back by a continuous force exerted above or below the center of resistance (see Fig. 2). The bow segment is soldered onto adhesive bases. (From J.S. Kim ${ }^{6}$, with the author's kind permission.)

formed regardless of the bone bases and the patient's individual muscular balance. Maximal intercuspation should not come at the expense of well-centered relations.

Specialist firms, such as Invisalign ${ }^{12}$ or Orthocaps ${ }^{5}$, for the time being, supply a series of plastic envelopes and show where to attach the asperities that fix the envelope.

These companies' services come at a cost, but greatly reduce the time the patient spends in the chair.
Those who do not wish to surrender to market forces can adhere to the rigorous methodology of the precursors of elastopositioning, Deroze and Lacout ${ }^{1}$.

These splints are still not elastic enough in our opinion, but are not too visible and allow good oral hygiene, and are better accepted than a series of brackets. They displace dental crowns perfectly and apices with a little more difficulty, and ensure precise intercuspation. 


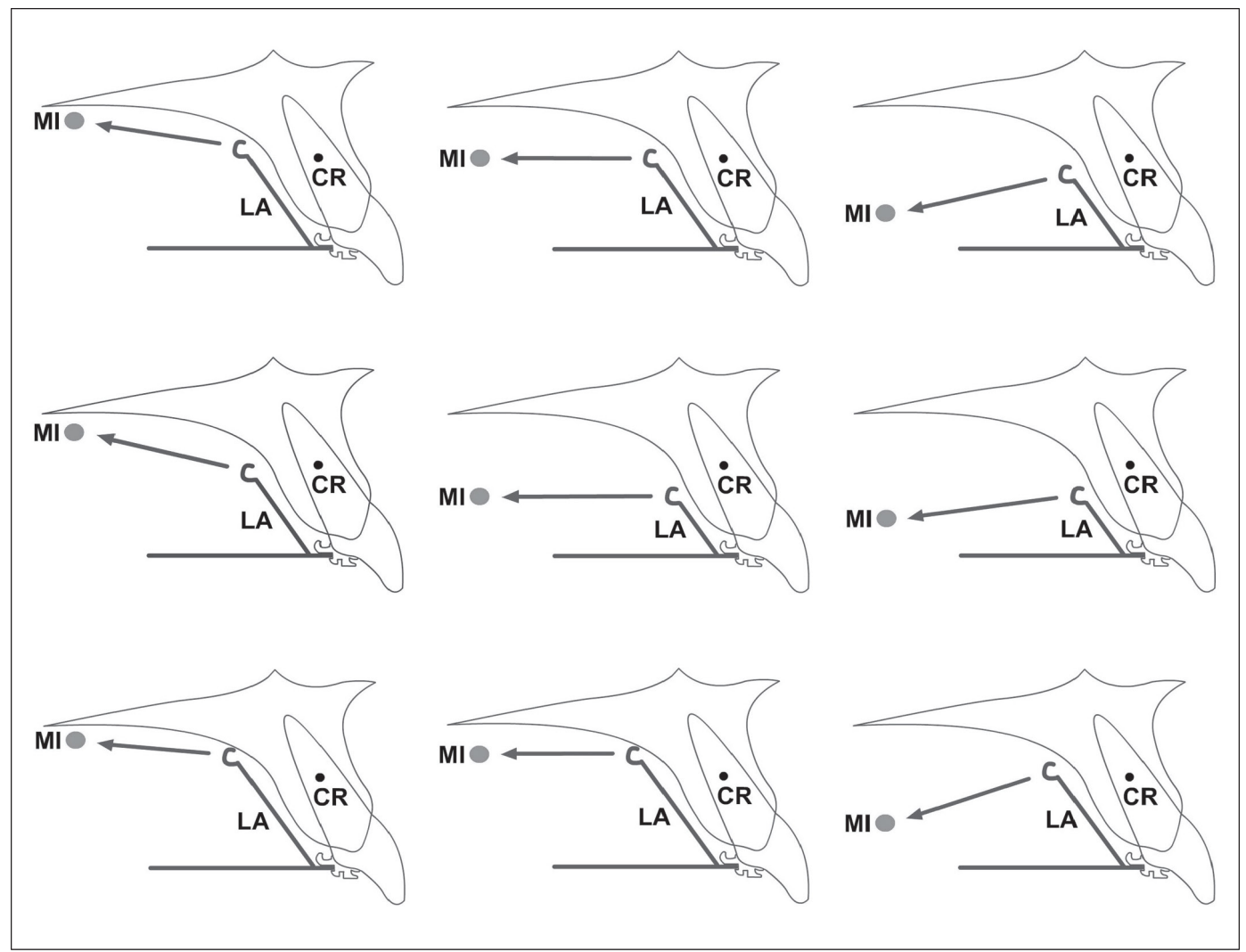

Figure 2

Analysis of maxillary incisor reaction according to level of application of retraction force with respect to the center of resistance and force direction. (From J.S. Kim ${ }^{6}$, with the author's kind permission.)

\section{CONCLUSION}

Orthodontics is not meant to make the patient's face conform to standard measurements, but to ensure health and beauty. Its future will be free of cephalometric analysis and brackets.

Conflicts of interest: The author declares no conflicts of interest.

\section{REFERENCES}

1. Deroze D, Lacout J. Élastofinition et stabilisation. In : Propositions orthodontiques/ classe II/situations critiques. Lejoyeux E, Flageul F. Paris : Quintessence, 2011. 
2. Duran Von Arx J, Smit M. Le système MultiFonctions (MFS). Diagnostic des fonctions orales. Orthod Bioprogressive 2013;21:5-13.

3. Fellus P. Orthodontie précoce en denture temporaire. Éditions CdP, 2003.

4. Hong RK, Heo JM, Ha YK. Lever arm and mini-implants system for anterior torque control during retraction in lingual orthodontic treatment. Angle Orthod 2005;75:129-41.

5. Khan W. Nouveaux concepts de traitements par aligneurs : le système Orthocaps. Orthod Fr 2014;85:253-62.

6. Kim JS, Kim AH, Kook YA, Chung KR, Nelson G. Analysis of lingual mass retraction combining a C-lingual retractor and a palatal plate. Angle Orthod 2011;81: 662-9.

7. Philippe J. La supraclusion et ses traitements. Paris : Éditions SID, 1995.

8. Philippe J. Convictions orthodontiques. Paris : Éditions SID, 2006.

9. Philippe J. À la recherche d'une ligne céphalométrique de référence. Orthod $\mathrm{Fr}$ 2012;83:217-23.

10. Philippe J. Vers la disparition des brackets ? Orthod Bioprogressive 2012;20:33-9.

11. Rollet $\mathrm{D}$. L'éducation fonctionnelle : prévention et interception des malpositions dentomaxillo-faciales. Améliorations des problèmes fonctionnels de l'adulte. Orthod Bioprogressive 2014;22:11-22.

12. Tuncay OC. The Invisalign System. Chicago: Quintessence Publishing, 2006. 